\title{
Faktor- Faktor yang Mempengaruhi Komitmen Dokter di Puskesmas untuk tidak Merujuk Kasus Non Spesialistik Pasien Peserta BPJS di Kota Semarang
}

\author{
Hendro Sucipto*,Chriswardani Suryawati**,Sutopo Patrio Jati**, \\ *Alumni Magister Ilmu Kesehatan Masyarakat Universitas Diponegoro, \\ **Fakultas Kesehatan Masyarakat, Universitas Diponegoro, Semarang \\ Email: mcendro224@yahoo.com
}

\section{ABSTRACT}

Patients who should be able to be treated at the health center (puskesmas) but because of some matters referred to and handled in a hospital, it is a waste of health costs. Hence, BPJS will pay more according to INA CBG's tariff. ${ }^{3}$

Advanced Health Facilities, in this case a hospital, is also object to having to deal with non-specialist cases, while the case can actually be completed at the first health facility. Handling non-specialist cases in hospitals leads to health services being less well targeted. The hospital will be very busy handling patients who are not supposed to, while patients who really need treatment in the hospital can be neglected. ${ }^{2}$

This study aims to analyze factors which influence the commitment of doctors not to refer to non-specialist cases in health centers in the city of Semarang

The study was conducted with a cross sectional quantitative research design. The data were collected by calculating the total results of the questionnaire measurements on each variable with a Likert scale on 73 doctors in 37 health centers spread across the city of Semarang. The study was conducted during March to May 2018.
The results showed that the number of non-specialist cases of BPJS Health participant patients was still relatively high. This has to do with the commitment of doctors at the health center not to refer to non-specialist cases. The most influence factor to the commitment of doctors not to refer to non-specialist cases was the doctor's perception of the completeness of facilities and infrastructure and the doctor's perception of his competence.

Keywords: commitment, non-specialist case, doctor of health center, BPJS.

\section{PENDAHULUAN}

Kasus rujukan pasien ke layanan sekunder untuk kasus-kasus yang seharusnya bisa dituntaskan di layanan primer adalah bukan hal yang baru dan tergolong masih tinggi dari tahun ke tahun. Hal itu berlangsung sejak sebelum diberlakukannya BPJS. Lebih tepatnya sejak era ASKES dan JAMSOSTEK, dimana pada masa itu persyaratan penyakit yang bisa di rujuk ke layanan sekunder atau tersier tidak terlalu ketat. Sehingga pada saat itu jumlah rujukan sulit dikontrol, setiap orang dengan mudah dapat memperoleh rujukan, sementara fasilitas 
kesehatan tingkat pertama praktis hanya dilewati.

Dari evaluasi dan monitoring yang dilakukan Dewan Jaminan Sosial Nasional (DJSN) menilai dalam setahun BPJS Kesehatan, sistem rujukan belum berjalan dengan lancar. Indikasinya, masih banyak peserta dirujuk ke Rumah Sakit padahal penyakitnya dapat ditangani di fasilitas kesehatan primer (FKTP). Indikasi lain, ada masyarakat yang mempersoalkan masalah kenyamanan dalam pelayanan Jaminan Kesehatan Nasional (BPJS). Dari evaluasi dan monitoring yang dilakukan Dewan Jaminan Sosial Nasional (DJSN) di semester I tahun 2015 persentase rujukan total (Rujukan kasus Spesialistik dan Non Spesialistik) masih tergolong tinggi, yakni mencapai 55 persen. Padahal persentase rujukan sudah ditetapkan maksimal 15 persen $^{9}$

Berdasarkan data BPJS Kesehatan Kantor Cabang Semarang Bulan Mei 2016, Jumlah peserta BPJS di Puskesmas di Kota Semarang sebanyak : 431.873 peserta, Jumlah Kunjungan Sakit : 34.108 (8,12\%), jumlah rujukan total (gabungan antara rujukan kasus spesialistik dan kasus nonspesiaalistik) : 4.163 (12,2\%), jumlah Rujukan Kasus Non Spesialistik (RNS) : $483(11,6 \%)$ dari rujukan total.

Berdasarkan data tersebut persentase Rujukan Non Spesialistik belum memenuhi harapan BPJS (< dari $5 \%$ ). Jumlah rujukan kasus non spesialistik puskesmas di Kota Semarang masih sangat tinggi yakni 11, 6\%. Dari 37 Puskesmas di Kota Semarang hanya empat Puskesmas yang memenuhi kategori skor aman untuk angka Rujukan Non Spesialistik yakni Puskesmas Krobokan (non rawat inap), Puskesmas Srondol (rawat inap), Puskemas Mangkang (non rawat inap), dan Puskesmas Karang Anyar (non rawat inap). Puskesmas yang lain masih dalam kategori skor kurang untuk RRNS.
Target pemenuhan rasio rujukan rawat jalan kasus non spesialistik oleh FKTP sesuai dengan kesepakatan antara BPJS Kesehatan dengan Asosiasi Fasilitas Kesehatan Tingkat Pertama, sebagai berikut; ${ }^{10}$ yang mana Target pada zona aman sebesar kurang dari 5\% setiap bulan dan target pada zona prestasi sebesar kurang dari 1\% setiap bulan.

Pasien yang seharusnya dapat ditangani di puskesmas namun karena suatu hal dirujuk dan ditangani di rumah sakit. Hal ini merupakan pemborosan biaya. Sebab jika harus dirujuk ke rumah sakit maka BPJS akan mengeluarkan biaya lagi sesuai dengan tarif INA CBG' s. Dengan kata lain angka rujukan yang tinggi karena rujukan non spesialistik adalah pemborosan biaya kesehatan, dan pelayanan kesehatan menjadi kurang tepat sasaran. Rumah sakit akan disibukkan oleh pasien yang tidak seharusnya, sementara pasien yang benarbenar perlu ditangani dirumah sakit bisa menjadi terabaikan.

\section{METODE PENELITIAN}

Penelitian ini menggunakan metode penelitian survei analitik, yaitu penelitian survei diarahkan untuk mempelajari hubungan antara variabel bebas dan variabel terikat dengan melakukan, pengukuran secara cross sectional dengan cara mengambil sampel dari suatu populasi dengan menggunakan kuesioner sebagai alat pengumpul data pokok. ${ }^{6}$ penelitian dilakukan pada bulan Maret 2018 sampai dengan bulan Mei 2018. Sampel diambil dengan menggunakan metode non probability sampling dan teknik purposif sampling. Seluruh dokter dari 37 Puskesmas di Kota Semarang yang memenuhi kriteria inklusif dan eksklusif.

Data dikumpulkan dengan kuesioner terstruktur, dan dokter mengisi sendiri kuesioner,. Sebelum digunakan, kuesioner diuji keterbacaannya pada 20 dokter di 
Kabupaten Semarang menguji validitas dan reabilitas dari masing-masing kuesioner. Pertanyaan dalam kuesioner digunakan untuk mengukur nilai total dari masing masing variabel dengan skala likert. Total hasil ukur diambil dari jumlah nilai dari masing-masing alternative pilihan jawaban. Total hasil ukur dengan nilai kriteria hasil di kategorikan dalam beberapa kategori.

Variabel yang diamati adalah persepsi dokter pada kompetensinya, persepsi dokter pada kompensasi yang ia dapatkan, persepsi dokter pada sarana dan prasarana kesehatan di puskesmas, tingkat konflik peran dokter, tingkat tanggung jawab sebagai seorang dokter, dan komitmen dokter pada organisasi puskesmas.

Data survei dianalisis dengan analisis bivariate dengan menggunakan uji chi squer dan dengan analisis multivariate dengan regresi logistik menggunakan perangkat lunak SPSS). Penelitian ini telah mendapatkan ethical clearance dari Komite Etik Fakultas Kesehatan Masyarakar Universitas Diponegoro..

\section{HASIL DAN PEMBAHASAN \\ Karakteristik responden / informan}

Responden penelitian pada metode kuantitatif ini berjumlah 73 orang. Karakteristik responden menurut usia, kebanyakan responden berusia paruh baya. Dengan rata-rata usia 40,85 tahun. usia termuda 34 tahun dan usia tertua adalah 58 tahun. menurut jenis kelamin responden, 45\% laki-laki dan 55\% perempuan.

Populasi dalam penelitian ini adalah semua dokter umum di puskesmas di Kota Semarang pada tahun 2016, yaitu sejumlah 90 orang. . Sampel dalam penelitian ini adalah semua dokter umum bekerja di puskesmas dengan masa kerja $>1$ tahun pada saat pengambilan sampel, bukan kepala puskesmas, dan tidak mengambil cuti $>$ dari 10 hari dalam tiga bulan terakhis yaitu sebanyak 73 orang dokter.

\section{Analisis Univariat}

Responden dengan kompetensi tinggi sebanyak 58 responden $(76,7 \%)$, dan Responden dengan kompetensi rendah sebanyak 17 responden $(23.3 \%)$.

Selain itu dari distribusi jawaban responden pada setiap item pernyataan kuisioner di temukan bahwa 42,3\% responden menyatakan bahwa mereka belum biasa menangani beberapa penyakit yang tergabung dalam daftar 155 jenis penyakit. $39,6 \%$ dokter merasa tidak mampu menanganinya beberapa penyakit yang tergabung dalam daftar 155 penyakit. Responden dengan persepsi dokter pada sarana dan prasarana tinggi sebanyak 54 responden (74,0\%), dan Responden dengan persepsi dokter pada sarana dan prasarana rendah sebanyak 19 responden (26,0\%).

Selain itu dari distribusi jawaban responden pada setiap item pernyataan kuisioner di temukan bahwa 42,3\% responden menyatakan bahwa peralatan di puskesmas belum cukup lengkap untuk menunjang penanganan 155 penyakit. 24,6\% responden menyatakan bahwa peralatan di puskesmas tidak berfungsi dengan baik. 42,4 $\%$ responden menyatakan bahwa peralatan di puskesmas tidak dikalibrasi secara rutin. $53,3 \%$ responden menyatakan bahwa ruang UGD tidak memenuhi standar pelayanan. Responden Kompensasi dokter tinggi sebanyak 50 responden (69,5\%), dan Responden dengan kompensasi dokter rendah sebanyak 23 responden $(31,5 \%)$.

Selain itu dari distribusi jawaban responden pada setiap item pernyataan kuisioner di temukan bahwa 47,9 \% dokter menyatakan bahwa besarnya tunjangan yang mereka terima belum sesuai dengan beban kerja mereka di puskesmas. 65,7\% dokter 
menyatakan bahwa dana kapitasi BPJS yang mereka terima setiap bulan sangat membantu perekonomian mereka. 58,5 \% dokter menyatakan bahwa mereka perlu bekerja dengan giat agar dana kapitasi BPJS dapat meningkat. $62,9 \%$ dokter menyatakan bahwa sistem KBK BPJS memotivasi mereka untuk meningkatkan dana kapitasi yang akan mereka peroleh bulan depan. $42,3 \%$ dokter menyatakan bahwa mereka tidak puas dengan cara membagi dana kapitasi BPJS di puskesmas. Responden dengan Konflik peran dokter tinggi sebanyak 52 responden $(71,2 \%)$, dan Responden dengan konflik peran dokter rendah sebanyak 21 responden $(28,8 \%)$.

Selain itu dari distribusi jawaban responden pada setiap item pernyataan kuisioner di temukan bahwa 75,3\% dokter menyakan bahwa sering kali mereka harus menangani kasus non spesialistik dengan kompetensi yang menurut mereka kurang. $57,4 \%$ dokter menyatakan bahwa mereka harus mengesampingkan aturan agar tidak terjadi konflik dengan pasien yang minta rujukan non spesialistik. 58,5\% dokter merasa bahwa mereka bekerja di bawah kebijakan yang sering berubah-ubah. Responden dengan Tanggung Jawab dokter tinggi sebanyak 49 responden $(67,1 \%)$, Responden dengan Tanggung Jawab dokter rendah sebanyak 24 responden (39.2\%).

Selain itu dari distribusi jawaban responden pada setiap item pernyataan kuisioner di temukan bahwa 75,3\% dokter tidak selalu memenuhi aturan dari BPJS terkait rujukan demi keselamatan pasien. Responden dengan Komitmen dokter tinggi sebanyak 44 responden $(39,7 \%)$, dan komitmen dokter rendah sebanyak 29 responden $(39,7 \%)$

\section{Analisis Bivariat}

Tabel 1.0. Hasil analisis bivariate dengan menggunakan uji Chi square

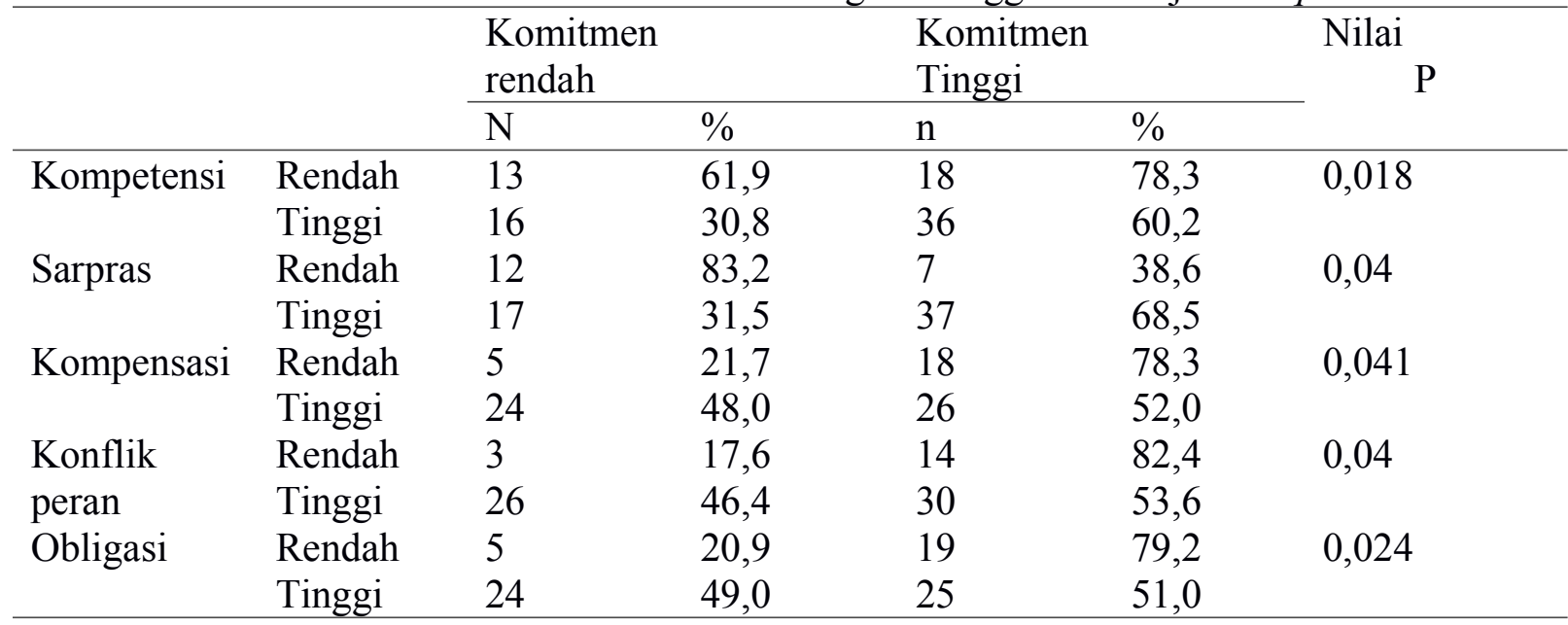

Hasil analisis hubungan antara persepsi dokter pada kompetensinya dengan komitmen dokter pada puskesmas, hasil uji statistik Chi-square diperoleh nilai $p$ value sebesar $0,018 \quad(<0,05)$ menunjukkan $\mathrm{Ha}$ diterima berarti ada hubungan antara persepsi dokter pada kompetensinya dengan komitmen dokter pada puskesmas. 
Hasil analisis hubungan antara persepsi dokter pada sarana dan prasarana puskesmas dengan komitmen dokter pada puskesmas, hasil uji statistik Chi-square diperoleh nilai $p$ value sebesar $0,04(<0,05)$ menunjukkan $\mathrm{Ha}$ diterima berarti ada hubungan antara persepsi dokter pada sarana dan prasarana puskesmas dengan komitmen dokter pada puskesmas.

Hasil analisis hubungan antara persepsi dokter pada kompensasi yang diterimanya dengan komitmen dokter pada puskesmas, hasil uji statistik Chi-square diperoleh nilai $p$ value sebesar $0,04(<0,05)$ menunjukkan $\mathrm{Ha}$ diterima berarti ada hubungan antara persepsi dokter pada kompensasi yang diterimanya dengan komitmen dokter pada puskesmas

Hasil analisis hubungan antara Konflik peran dokter dengan komitmen dokterpada puskesmas, hasil uji statistik Chi-square diperoleh nilai $p$ value sebesar $0,04(<0,05)$ menunjukkan $\mathrm{Ha}$ diterima berarti ada hubungan antara konflik peran dokter dengan komitmen dokter pada puskesmas.

Hasil analisis hubungan antara Tanggung Jawab dokter dengan komitmen dokter pada puskesmas, hasil uji statistik Chi-square diperoleh nilai $p$ value sebesar $0,024(<0,05)$ menunjukkan $\mathrm{Ha}$ diterima berarti ada hubungan antara Tanggung Jawab dokterdengan komitmen dokter pada puskesmas.

\section{Analisis Multivariat}

Tabel 1.1. Hasil analisis multivariate regresi logistik

\begin{tabular}{|c|c|c|c|c|c|c|c|c|}
\hline & \multirow{2}{*}{$\begin{array}{l}\text { Koefi } \\
\text { sien }\end{array}$} & \multirow[t]{2}{*}{ S.E } & \multirow[t]{2}{*}{ Wald } & \multirow[t]{2}{*}{$\mathrm{df}$} & \multirow{2}{*}{$\begin{array}{l}\text { Nilai } \\
\mathrm{P}\end{array}$} & \multirow[t]{2}{*}{ OR } & \multicolumn{2}{|c|}{ IK95\% } \\
\hline & & & & & & & Min & Max \\
\hline $\begin{array}{l}\text { Kompetensi } \\
\text { tinggi }\end{array}$ & 1,276 & 0.577 & 4.899 & 1 & 0.027 & 3,584 & 1.157 & 11.09 \\
\hline $\begin{array}{l}\text { Kompensasi } \\
\text { tinggi }\end{array}$ & -1.019 & 0.627 & 2.640 & 1 & 0.104 & 0.361 & 0.106 & 1,234 \\
\hline $\begin{array}{l}\text { Obligasi } \\
\text { tinggi }\end{array}$ & -0.992 & 0.617 & 2.586 & 1 & 0.108 & 0.371 & 0.111 & 1.242 \\
\hline Constanta & 0.963 & 0.745 & 1.671 & 1 & 0.196 & 2.620 & -- & -- \\
\hline
\end{tabular}

Tabel tersebut diatas adalah hasil analisis multivariate model terakhir setelah di lakukan metode Backward. Adapun interprestasinya dimana nilai $\mathrm{p}$ uji Wald dari koefisian yang nilainya lebih kecil 0.05 adalah pada variabel persepsi kompetensi tinggi. Dan pada rentang interval kepercayaan dari Odds Rasio (OR) tidak ada angka satu (suatu variabel bebas akan berhubungan secara bermakna dengan variabel terikat ketika mempunyai nilai $\mathrm{p}$ uji Wald dari koefisien yang nilainya lebih kecil dari 0,05 dan tidak melewati angka satu pada interval kepercayaan dari OR). ${ }^{12}$
Maka dapat di tarik kesimpulan bahwa hanya variabel kompetensi tinggi saja yang berhubungan secara bermakna dengan variabel komitmen dokter di puskesmas untuk tidak merujuk kasus non spesialistik pasien peserta BPJS di Kota Semarang.

Nilai Odds Rasio (OR) pada persepsi sarana dan prasarana tinggi adalah 3,584 artinya kemungkinan subyek berkompetensi tinggi untuk berkomitmen tinggi untuk tidak merujuk kasus non spesialistk adalah 3,584 kali kemungkinan subyek pada kompetensi rendah 


\section{KESIMPULAN}

Mutu pelayanan kesehatan di Kota Semarang masih dirasakan belum memuaskan. Hal itu terjadi karena masih terlalu tinggi angka rujukan kasus non spesialistik pasien pasien terutama pasien BPJS. Sehingga pasien yang seharusnya dapat ditangani di puskesmas harus di tangani di rumah sakit. Hal tersebut membuat pelayanan kesehatan di faskes tingkat kedua dan ketiga menjadi kewalahan dan pelayanan menjadi kurang fokus terhadap pasien-pasien yang seharusnya memang harus di tangani di faskes lanjutan tersebut.

Di samping itu akan terjadi pembengkakan biaya kesehatan karena pasien yang seharusnya cukup hanya dibiayai dengan dana kapitasi BPJS harus di tambah dengan paket biaya INA-CBGs.

Selain itu komitmen yang rendah dari dinas kesehatan dalam memback up puskesmas dalam pelaksanaan pelayanan BPJS membuat puskesmas mengalami kesulitan dalam menyediakan sarana dan prasarana kesehatan yang layak untuk menunjang pelayanan 155 penyakit yang memang harus di tangani di puskesmas.

Tingginya angka rujukan kasus non spesialistik tidak terlepas dari komitmen dokter untuk tidak merujuk kasus non spesialistik pasien peserta BPJS di mana keputusan untuk merujuk atau tidak merujuk kasus non spesialistik sebagian besar ada ditangan dokter.

Namun demikian dalam mengambil keputusan dokter dihadapkan pada beberapa hal, diantaranya adalah seberapa tingginya persepsi dokter pada kompetensinya guna menunjang penangan suatu kasus. Semakin tinggi persepsi dokter pada kompetensinya akan membuat semakin tingginya rasa percaya diri seorang dakter untuk menangani suatu kasus penyakit. Dan dengan demikian semakin tinggi pula komitmen dokter untuk tidak merujuk kasus non spesialistik

\section{DAFTAR PUSTAKA}

1. BPJS Kesehatan. Peraturan BPJS Nomor 1 tahun 2014 tentang penyelenggaraan jaminan kesehatan. Jakarta; 2014

2. BPJS Kesehatan. DJSN anggap system rujukan belum lancar: BPJS Kesehatan; 2015.

http://www.hukumonline.com/berita/bac a/lt55142410c763f/djsn-anggap-sistemrujukan-bpjs-belum-lancar. Diakses tanggal 16-10-2016

3. BPJS Kesehatan. Panduan Praktis Gate Keeper Concept Faskes BPJS Kesehatan. Jakarta : BPJS Kesehatan; 2013

4. Wulandhani A, dan Hafisurrachman S. M. Gambaran Factor-Faktor Yang Mempengaruhi Kasus Rujukan Rawat Jalan Tingkat Pertama Peserta Askes Sosial PT Askes (Persero) Cabang Metro Di Puskesmas Sumber Sari Bantul Kota Metro Tahun 2012. Jurnal Manajemen Pelayanan Kesehatan FKM UI 2013; 6(02), 87-95. 13.

5. Indonesia. Undang-Undang Republik Indonesia Tentang Praktik Kedokteran. UU Nomor 29 Tahun 2004, LN.No. 116, TLN No.4431

6. Notoatmodjo. 2010. Metodologi Penelitian Kesehatan. Jakarta : PT. Rineka Cipta

7. Sopiyudin Dahlan. M. statistic untuk kedokteran dan kesehatan. Jakarta: Epidemiologi Indonesia 2014.

8. Sopiyudin Dahlan. M. Analisis Multivariate Regresi Logistik. Jakarta: Epidemiologi Indonesia 2012.

9. BPJS Kesehatan. DJSN anggap system rujukan belum lancar: BPJS Kesehatan; 
2015.

http://www.hukumonline.com/berita/bac a/lt55142410c763f/djsn-anggap-sistemrujukan-bpjs-belum-lancar. Diakses tanggal 16-10-2016

10.BPJS Kesehatan. Peraturan BPJS Nomor 2 tahun 2015 tentang Norma Penetapan Besaran Kapitasi Dan Pembayaran Kapitasi Berbasis Pemenuhan Kolitmen Pelayanan Pada fasilitas Kesehatan Tingkat Pertama, Jakarta; 2015

11. Ather Ali, ND,MPH,MHS, David L. Katz, MD,MPH. Disease Prevention and Health Promotion. American Journal Of Preventive Medicine

12. Sopiyudin. Dahlan, M. Analisis Multivariate Regresi Logistik. Jakarta: Epidemiologi Indonesia 2012. 